\title{
Relação entre o tipo de contrato de trabalho e a dedicação do trabalhador no emprego: evidências para as regióes metropolitanas brasileiras
}

Tatiane Almeida de Menezes Professora adjunta do Departamento de Economia - UFPE Professora da Pós-Graduação em Economia - PIMES Pesquisadora do CNPq.

Paulo Aguiar do Monte Professor adjunto do Departamento de Economia - UFPB Professor da Pós-Graduação em Economia - PPGE/UFPB

\section{Palavras-chave}

contrato temporário, esforço, horas de trabalho, seleção adversa.

Classificação JEL J24, J41, C25

\section{Key Words \\ temporary work, effort, hours worked, adverse selection.}

JEL Classification J24, J41, C25

\section{Resumo}

Este artigo analisa a relação entre dedicação/ esforço do trabalhador no emprego e vínculo contratual. Parte-se da hipótese de que o tipo de vínculo contratual de trabalho poderia implicar incentivos adicionais de esforço. Por meio dos microdados da Pesquisa Mensal de Emprego (PME), de 2006 e 2007, utilizou-se como proxy de esforço as informaçóes relativas à subocupação, à subremuneração e à falta ao trabalho. Inicialmente, observou-se que existem diferenças significativas de perfil entre os trabalhadores, conforme o seu vínculo contratual. Em seguida, os resultados das estimações mostraram que a disposição do trabalhador se altera conforme seja a proxy de dedicação utilizada. De modo geral, os trabalhadores temporários não costumam a disponibilizar horas extras de trabalho e têm chances maiores de serem subremunerados. Por fim, as estimaçóes feitas não indicam mudança significativa de comportamento entre os trabalhadores, caso se modifique o seu vínculo contratual.

\section{Abstract}

This paper studies the relationship between employee effort and employment contracts. It starts with the hypothesis that the type of employment contract could result in additional incentives for effort. Using indicators for effort (extra hours of work, salary below the minimum wage and absenteeism) taken from the Monthly Employment Survey (PME) in 2006 and 2007, it was observed that there are significant differences in profile between the workers, according to their contracts. In turn, the estimation results showed that depending on the indicator used to measure the effort of the worker, the effort expended by workers changes. Furthermore, temporary workers tend not to provide extra hours of work and are more likely to receive a salary below the minimum wage. Finally, the estimates made do not indicate a significant change in behavior among workers, when their contracts are modified. 


\section{1_Introdução}

Uma importante característica das relaçóes de trabalho refere-se ao tipo de vínculo contratual do trabalhador, mais especificamente ao tempo de duração do trabalho, isto é, se permanente (indeterminado) ou temporário (determinado). Existe forte evidência na literatura que as características do vínculo empregatício afetam a dedicação/esforço do trabalhador no desempenho das suas atividades. A razão dessa variação de esforço/empenho do trabalhador pode estar associada ao grau de proteçáo do trabalho (Bradley et al., 2007).

Ichino e Riphahn (2001) e Engellandt e Riphahn (2005), em artigos para o mercado de trabalho da Alemanha e da Itália, respectivamente, mostraram que é justamente nos setores nos quais o grau de proteção ao trabalhador é maior que são verificadas o maior número de faltas ao trabalho, sugerindo, portanto, que esses trabalhadores sejam menos esforçados no desempenho de suas atividades. Para os autores, os resultados indicam que quanto menor o risco de perda do emprego, menor é o esforço do trabalho. $\mathrm{O}$ conceito de trabalho temporário, no Brasil, é definido com base na Lei no 6.019, de 3 de janeiro de 1974, que o classifica como aquele prestado por pessoa física a uma empre$\mathrm{sa}$, para atender à necessidade transitória de substituição de seu pessoal regular e permanente ou a acréscimo extraordinário de serviços. Sendo assim, observa-se que, em sua própria origem conceitual, o trabalho temporário deve ser transitório, visando a um vínculo permanente das relaçóes de trabalho. Neste contexto, a natureza do vínculo contratual passa a ser como um limitador referente à proteção do trabalhador no mercado de trabalho. Por isso, os trabalhadores temporários têm o incentivo de modificar a sua situação no mercado de trabalho, enviando sinais de esforço ao seu empregador para se tornar permanente (Booth $e t$ al., 2002; Bradley et al., 2007).

Essa formalização das relaçóes de trabalho entre empregado e empregador é vista como um problema principal-agente por conta da existência de informaçóes assimétricas entre as partes. No caso do empregador, o ideal seria conseguir informaçóes acerca do esforço despendido pelo trabalhador; entretanto, os custos envolvidos para conseguir essa informação acabam impedindo tal objetivo. Já para o empregado, o nível de esforço demonstrado na execução de suas atividades seria um instrumento adicional na obtenção de um vínculo permanente (Esteves, 2008). O número de contratos temporários tem aumentado significativamente no Brasil. Segun- 
do informações da Relação Anual de Informações Sociais (RAIS) do Ministério do Trabalho e Emprego (MTE), em 1997, cerca de 4,16\% dos trabalhadores ocupados no mercado formal possuíam contrato temporário de emprego. Em 2007, esse percentual havia alcançado a marca de $8,85 \%$. Tal tendência natural é observada na maioria dos países desenvolvidos (Booth et al., 2002). Embora se saiba que parte substancial dos trabalhadores com contrato temporário prefere ter um emprego com contrato indeterminado, essa escolha é feita pelas empresas que procuram flexibilizar e reduzir os custos, recorrendo, muitas vezes, aos contratos temporários. Para Nannicini (2004), a permissão de formalização de contratos temporários representa uma das maiores intervenções feitas nos últimos anos, no mercado de trabalho, onde os efeitos dessa intervenção ainda são incertos para o empregador e o empregado. A maior parte das pesquisas sobre esse tema tem procurado analisar as seguintes questôes: a razão da existência dos contratos temporários de emprego, os fatores que explicam o seu crescimento nos últimos anos, as características dos trabalhadores ocupados com vínculo temporário e suas relações de trabalho e a transição do trabalho temporário para o trabalho permanente.
Neste contexto, este estudo procura abordar um tema pouco explorado no Brasil: a relação existente entre dedicação/esforço despendido pelo trabalhador no mercado de trabalho e o seu tipo de vínculo contratual (permanente ou temporário). A hipótese a ser testada no presente artigo é que trabalhadores com vínculo temporário possuem nível de esforço mais elevado em relação aos com vínculo permanente, sendo a dedicação ao trabalho encarada como uma estratégia do trabalhador para se tornar um empregado permanente. A hipótese alternativa seria que os trabalhadores mais competentes já são os permanentes, logo, seriam os que apresentariam maior nível de dedicação ao trabalho. Deve-se ressaltar, porém, que no Brasil o contrato por prazo indeterminado (vínculo permanente) não garante qualquer estabilidade no emprego.

Desta forma, este artigo procura analisar o efeito do tipo de contrato no esforço despendido pelo trabalhador. A literatura internacional (Barmby et al., 1991; Jimeno; Cortés, 1996; Booth et al., 2002; Engellandt; Riphahn, 2005; Barmby, 2002) sugere que sejam utilizadas como proxy para a dedicaçáo do trabalhador variáveis como: assiduidade, subocupação e subremuneração. Definem-se trabalhadores subocupados como aqueles que estão trabalhando menos de 40 horas semanais 
e que gostariam de trabalhar horas adicionais. Trabalhadores subremunerados, por sua vez, são aqueles cujos rendimentos habitualmente recebidos no mês de referência são proporcionalmente inferiores ao número de horas habitualmente trabalhadas. Por fim, o número de faltas mede a assiduidade do trabalhador. Como fonte de dados, empregam-se os microdados da Pesquisa Mensal de Emprego (PME) de 2006 e 2007. Além desta introdução, este trabalho está dividido em mais seis sessões. $\mathrm{Na}$ sessão seguinte, é feita uma revisão da literatura sobre a relação existente entre vínculo contratual e dedicação ao trabalho, enfocando as primeiras evidências da literatura e as hipóteses traçadas no estudo. Na sessão três, descrevem-se a metodologia utilizada e as informaçóes acerca do banco de dados. Na quarta sessão, é abordada a estratégia empírica utilizada, ao passo que, na sessão seguinte, são mostrados os resultados da análise descritiva e das estimações. Por fim, têm-se, na última sessão, as considerações finais.

\section{2_A relação entre dedicação ao trabalho e tipo de contrato}

Comparando o mercado de trabalho do Brasil com o de outros países desenvolvidos ou em processo de desenvolvimento, observa-se que o mercado brasileiro pos- sui características aparentemente contraditórias como alta rotatividade, associada a um elevado custo de contratação e demissão. O Brasil possui uma legislação trabalhista bastante rígida, o que, segundo Amadeo e Camargo (1996) e Barros et al. (1999), é identificado tanto na admissão quanto na demissão do trabalhador.

Os principais custos associados à admissão dizem respeito à seleção e ao treinamento de pessoal, enquanto os custos de demissão seriam basicamente associados ao custo financeiro (multa de $50 \%$ do FGTS). Devem-se, no entanto, levar também em consideração o custo de oportunidade e a queda na produtividade acarretada pela rotatividade indesejada do trabalhador. Amadeo e Camargo (1996) e Barros et al. (1999) argumentam que tais custos quase sempre têm efeito inverso do planejado, contribuindo para elevar ainda mais a rotatividade no país, como, por exemplo, a aplicação da multa do FGTS, que pode estimular o trabalhador a induzir a própria demissão visando ao recebimento dos recursos do FGTS. Tal peculiaridade é apontada como um dos principais obstáculos à geração de emprego e à redução da informalidade no país. Esses argumentos, no entanto, são questionáveis, uma vez que ocorreram medidas importantes de flexibilização trabalhista nas últimas décadas, e os índices de 
desemprego e da informalidade não se reduziram. ${ }^{1}$ Todavia, comparativamente a outros países, principalmente ao mercado de trabalho europeu, ${ }^{2}$ não restam dúvidas de que, no Brasil, a rigidez e o custo dos contratos dificultam maior expansão no volume de empregos gerados. $\mathrm{O}$ termo "flexibilização do emprego" refere-se à adequação das relaçóes existentes ofertantes e demandantes de mão de obra para responder às variaçóes cíclicas ou às mudanças estruturais da economia, estando associado à renúncia de algumas normas jurídicas que regem o contrato de trabalho, tais como as que governam os encargos sociais e trabalhistas da admissão e da demissão (Jatobá; Andrade, 1993).

Para muitos trabalhadores e empregadores, o uso do recurso a contratos de duração determinada acaba funcionando como uma fase de experimentação ou pré-

${ }^{1}$ Gomes e Lourenço (2008)

destacam que a flexibilização das relaçóes no mercado de trabalho, na prática, tem sido acompanhada da precarização das condições de trabalho e concentração de renda em favor do capital. Para Jatobá e Andrade (1993), um provável resultado desse tipo de flexibilização é acentuar a segmentação do mercado de trabalho pela multiplicação do emprego precário e subremunerado.

Blanchard (2004), por

sua vez, argumenta que

a ampliação da oferta de

trabalho decorrente da

flexibilização das regras

trabalhistas produziria

redução da taxa de

desemprego de equilíbrio

de longo prazo sem

reduçáo do salário real de

equilíbrio de longo prazo.

${ }^{2}$ Ver Mangan (2000) -recrutamento (Cahuc; Postel-Vinay, 2002), sendo bastante comum durante os ciclos econômicos (Holmlund; Storrie, 2002). É importante citar, contudo, que o contrato por prazo indeterminado náo garante a estabilidade no emprego e, somado às altas taxas de rotatividade apresentadas no Brasil, o risco de perder o emprego parece estar sempre presente no cotidiano dos trabalhadores brasileiros. A flexibilização das relações de emprego está associada aos baixos níveis de investimento em treinamento (Green; Heywood, 2007), aos baixos salários (Booth et al., 2002) e ao aumento da insegurança no trabalho (Blanchard; Landier, 2002). Ao mesmo tempo, contratos de trabalhos mais flexíveis estáo relacionados às altas taxas de inserção ocupacional em trabalhos de vínculo permanente (quando comparados com a taxa de procura por emprego) via promoção interna dentro da empresa (Green; Leeves, 2004).

A literatura, principalmente a internacional, tem apontado que o tipo de contrato assinado entre empregado e empregador tem efeito sobre o comportamento do trabalhador. Tal questão tem chamado a atenção dos pesquisadores, principalmente no contexto internacional. As principais linhas de pesquisa sobre o tema referem-se à questão da proteção ao emprego e à investigação sobre os riscos inerentes à contratação. Ichino 
e Riphahn (2001) e Riphahn e Thalmaier (2001) encontraram elevados aumentos no número de faltas ao trabalho entre os trabalhadores italianos e alemães, respectivamente, quando do período final do vencimento dos seus contratos temporários, caso não houvesse nenhuma sinalização positiva por parte do empregador. Quando ocorre algum indicativo ou possibilidade de mudança no vínculo empregatício do trabalhador temporário, é de se esperar que esses tenham incentivos em demonstrar elevado nível de esforço no trabalho. Segundo Engellandt e Riphahn (2005), isso ocorre porque as empresas tendem a usar o contrato temporário para selecionar potenciais empregados permanentes e também porque existe prova direta de que a contrataçáo temporária pode servir como mecanismo para contratos mais atraentes de emprego. Jimeno e Cortés (1996) mostraram haver correlaçáo positiva entre o esforço do trabalhador (medido pelo número de horas de não remunerado) e a probabilidade de se avançar para um contrato permanente ${ }^{3}$.

De acordo com o estudo de Booth et al. (2002) sobre o mercado de trabalho britânico, cerca de 38\% dos trabalhadores com contrato temporário conseguiram, após o término do contrato, alterar seu vínculo contratual para permanente. Bradley et al. (2007) apresentam um modelo

de decisão para o trabalhador com contrato temporário. Os autores supóem que o trabalho gera uma utilidade negativa que é compensada pelo salário (w). Dois fatores são empregados para mensurar a desutilidade do trabalho: o esforço e a falta de assiduidade ao emprego, ambos proxies que demonstram o comprometimento do trabalhador. Considerando que a dedicação/esforço despendido pelo trabalhador causa desutilidade e que a sua falta ou ausência (A) no trabalho a diminui, pode-se concluir que tanto o salário como a ausência no trabalho estão positivamente relacionados com a utilidade esperada do trabalhador. Assim temos:

$$
U_{i}=U\left(w, A_{i}\right)=w+A_{i}
$$

Por sua vez, a utilidade do trabalhador com vínculo temporário pode ser expressa como:

$$
r V_{i}^{E T}=w_{t}+A_{i}+(1-g) C\left(A_{i}\right)\left(V^{U}-V_{i}^{E T}\right)
$$

Onde, $r$ é a taxa de desconto, $V^{E T}$ é a utilidade do trabalhador com vínculo temporário e $V^{U}$ é a utilidade para o trabalhador desempregado.

Por hipótese, o risco de o trabalhador ser demitido é diretamente proporcional a sua ausência ou ao pouco esforço no trabalho. Neste modelo, o maior risco

\footnotetext{
3 Johanson e Palme (1996; 2002) argumentam que as ausências dos trabalhadores podem ser minimizadas através de políticas adotadas pelas empresas. A redução dos benefícios concedidos aos trabalhadores, por exemplo, contribuiu para diminuir o número de faltas.
} 
para o trabalhador temporário é não ter seu contrato de trabalho renovado. Desta forma, a variável $g(0<g<1)$ é uma medida de sucesso, que capta a taxa na qual os contratos temporários são renovados e, por conseguinte, transformados em permanentes. Quanto mais próximo de 1 for o $g$, maiores são as chances de o contrato ser renovado, e, quanto mais próximo de zero, o inverso. A probabilidade de renovação (sucesso) é uma função convexa positiva em relação à ausência do trabalhador; $C(A)\left(C^{\prime}=>0\right.$ e $\left.C^{\prime \prime}=>0\right)$.

O trabalhador maximiza sua utilidade no emprego temporário ao escolher o nível de esforço que minimiza o risco de insucesso, ou desemprego (A). A solução ótima indica que o nível de esforço tende a aumentar quando o risco do insucesso aumenta. Outra hipótese importante é que o nível de esforço afeta a probabilidade de obtenção de um emprego permanente. A utilidade esperada do trabalhador com vínculo permanente de emprego $E\left(r V^{E T}\right)$ é dado por:

$$
E\left(r V_{i}^{E T}\right)=E\left(w_{P}\right)+A_{i}+(1-\gamma) C\left(A_{i}\right)\left(V_{i}^{E T}-E\left(V_{i}^{E T}\right)\right)
$$

A probabilidade de o trabalhador ter seu vínculo transformado em permanente é $(1-\gamma) C\left(A_{i}\right)$. Ou seja, a proba- bilidade de transição é função negativa da ausência, $C(A)$. A variável $\gamma$ representa a proporção de contratos temporários que podem ser convertidos para contratos permanentes. Se $\gamma=0$, todos os contratos temporários estão sujeitos à transição, e, caso $\gamma=1$, nenhum contrato temporário está sujeito à transição.

Logo, cabe ao trabalhador determinar o seu nível de dedicação baseado na comparação entre o benefício marginal e o custo marginal de conseguir um contrato permanente de emprego. A solução ótima sugere que os trabalhadores vão diminuir as faltas e aumentar o seu nível de esforço para que suas chances de transição sejam maiores. Segundo Bradley et al. (2007), esse modelo sugere que o trabalhador de contrato temporário estará sujeito a estímulos para reduzir o número de faltas no trabalho; visto que, assim, terão aumentadas suas chances de transição do contrato temporário para o contrato o permanente. É, neste contexto, que definimos o objetivo deste trabalho. Assim, pretende-se testar, mediante hipóteses, se a tese adotada nos estudos internacionais pode ser aceita para a realidade brasileira, ou seja, se os trabalhadores com vínculo temporário de emprego são mais esforçados, comparativamente aos trabalhadores com vínculo permanente. 


\section{3_Descrição dos dados}

O trabalho foi desenvolvido com base nos microdados da Pesquisa Mensal de Emprego (PME) de 2006 e 2007, cobrindo as seguintes Regiōes Metropolitanas do Brasil: Recife (RMR), Salvador (RMS), Belo Horizonte (RMBH), São Paulo (RMSP), Rio de Janeiro (RMRJ) e Porto Alegre (RMPA).

A PME tem periodicidade mensal e segue um esquema de painéis rotativos, onde um conjunto de domicílios é selecionado em cada conjunto de setores censitários selecionados. ${ }^{4}$ Cada domicílio é acompanhado por quatro meses consecutivos, depois é retirado da amostra por oito meses consecutivos, entrando novamente por mais quatro meses seguidos, quando é definitivamente excluído. Para a formação da nossa amostra, foram selecionados apenas os trabalhadores empregados, com idade entre 18 e 70 anos; desconsiderando os ocupados no Serviço Militar e aqueles que não tinham respondido às perguntas relevantes para o estudo. Considerando que na pesquisa consta mais de uma entrevista por trabalhador, adotaram-se como critério para a construção do pooling de observações duas entrevistas de cada trabalhador. Como primeira entrevista, definiu-se o momento inicial em que o trabalhador foi entrevistado no ano de 2006, e, como segunda entrevista, o momento em que o traba- lhador foi entrevistado após 12 meses da primeira entrevista. Desta forma, para cada entrevista, existe um período intervalar de 12 meses. $^{5}$ Após a realização de todos os filtros, inclusive com a exclusão dos casos omissos (missing), chegou-se a uma amostra final de 31.704 observaçóes, o que corresponde a 15.852 observações em cada entrevista.

Infelizmente, não existe uma medida que seja capaz de captar de forma direta o esforço e/ou o interesse do empregado no trabalho (variável latente). É possível, porém, construir indicadores que, de forma indireta, permitam apreender as informações de interesse, ou seja, o grau de dedicação/esforço do trabalhador. Com esse intuito, seguindo a literatura (Barmby et al., 1991; Jimeno; Cortés, 1996; Booth et al., 2002; Engellandt; Riphahn, 2005), foram construídas três variáveis binárias de dedicação/esforço: $s u$ bremuneração, subocupação e ausência no trabalho (assiduidade).

A variável subremuneração é igual à unidade se o salário hora do trabalhador for inferior à média de sua categoria. A intuição é que o trabalhador que está fazendo horas extras sem compensação salarial revela nível de dedicação acima da média. A subocupação é definida igual a se o empregado, com menos de 40 horas semanais, tivesse condiçóes de
${ }^{4}$ Sobre emparelhamento de indivíduos na PME, ver Ribas e Soares (2010).

${ }^{5}$ A utilização de um painel de 12 meses, com apenas duas entrevistas, deve-se à questáo amostral. Se aplicássemos a metodologia de quatro entrevistas consecutivas, a amostra sofreria redução para apenas $15 \%$ do total considerado nesta análise. 
Tabela 1_Características da amostra, segundo o tipo de contrato, em percentual 2006 e 2007

\begin{tabular}{|c|c|c|}
\hline Características & $\begin{array}{l}\text {. . . Tp̣o de } \\
\text { Permanente }\end{array}$ & $\begin{array}{l}\text { ontrato } \\
\text { Temporário }\end{array}$ \\
\hline \multicolumn{3}{|l|}{ Pessoais } \\
\hline Homem & 62,77 & 51,24 \\
\hline De 16 a 25 & 21,57 & 46,14 \\
\hline De 26 a 40 & 44,70 & 34,23 \\
\hline De 41 a 70 & 33,73 & 19,63 \\
\hline Chefe de família & 52,15 & 31,16 \\
\hline Escolaridade (sem instrução) & 1,07 & 1,42 \\
\hline Escolaridade (de 1 a 3 anos de estudo) & 3,42 & 2,10 \\
\hline Escolaridade (de 4 a 7 anos de estudo) & 17,74 & 11,69 \\
\hline Escolaridade (de 8 a 10 anos de estudo) & 16,96 & 10,86 \\
\hline Escolaridade (11 ou mais anos de estudo) & 60,81 & 73,93 \\
\hline \multicolumn{3}{|l|}{ Do trabalho } \\
\hline Tempo (até 1 mês) & 0,75 & 4,49 \\
\hline Tempo (de 1 mês até 1 ano) & 15,92 & 45,69 \\
\hline Tempo (de 1 ano até 2 anos) & 13,72 & 19,48 \\
\hline Tempo (mais de 2 anos) & 69,61 & 30,34 \\
\hline Tamanho (de 1 a 5 trabalhadores) & 10,19 & 10,26 \\
\hline Tamanho (de 6 a 10 trabalhadores) & 6,38 & 4,42 \\
\hline Tamanho (11 ou mais trabalhadores) & 83,42 & 85,32 \\
\hline Setorprivado & 95,34 & 63,30 \\
\hline Indústria & 28,46 & 17,90 \\
\hline Comércio & 19,21 & 8,31 \\
\hline Serviços & 52,00 & 73,26 \\
\hline Subocupadohoras & 1,93 & 8,61 \\
\hline Subocupadosalario & 11,07 & 11,61 \\
\hline Ausência no trabalho & 2,90 & 2,40 \\
\hline Número de observaçóes & 30.369 & 1.335 \\
\hline
\end{tabular}

Fonte: Pesquisa Mensal de Emprego (2006 e 2007). Cálculos próprios. trabalhar horas adicionais, porém não o faz. Entende-se que os subocupados são aqueles que estão trabalhando menos do que poderiam. Neste caso, quanto menos subocupação maior o esforço. Finalmente, a frequência é avaliada com base no número de faltas, que será igual a uma todas as vezes em que o funcionário revelasse ter se ausentado do emprego, de forma justificada ou não. As informações para construção das proxies acima advêm dos microdados da Pesquisa Mensal de Emprego (PME), de 2006 e 2007. O modelo foi, então, estimado para cada uma das três proxies de esforço acima descrito.

A análise descritiva desta amostra está presente na Tabela 1 . O número de trabalhadores com contrato temporário é de 1.335 (4,2\% do total da amostra), o que ratifica seu baixo índice no mercado brasileiro. É possível identificar também que os trabalhadores subocupados e subremunerados apresentam em sua maioria vínculo de trabalho temporário. Já a variável ausência (falta ao trabalho) sugere que os trabalhadores com contrato temporário faltam menos, comparativamente aos trabalhadores com vínculo permanente de emprego.

Realizando um teste de diferença de média dessas variáveis, encontra-se que, para subocupação, ao contrário do esperado, rejeita-se $\mathrm{H}_{0}$ a $5 \%(\mathrm{t}=-16,3)$, indo de 
encontro ao modelo, visto que a princípio era esperada uma maioria de trabalhadores subocupados com vínculo permanente. Esse resultado, entretanto, não está controlado pelas características da empresa e do trabalhador, o que de certa forma mascara o resultado. $\mathrm{Na}$ próxima seção, uma análise mais minuciosa será desenvolvida. Quando o mesmo teste é feito para as variáveis subremuneração e ausência $(\mathrm{t}=-0,6187$ e $\mathrm{t}=1,0776$, respectivamente), no entanto, não é possível rejeitar $\mathrm{H}_{0}$.

Para Bradley et al. (2007), o efeito do risco da perda do emprego e das oportunidades de promoção tem intensidade diferente entre os trabalhadores, sendo, em geral, mais forte para os trabalhadores temporários. Portanto, as informações contidas na Tabela 1 vão ao encontro dos resultados descritos na literatura.

No que diz respeito ao gênero dos trabalhadores, a análise da Tabela 1 sugere que a participação masculina seja em torno de $10 \%$ maior nos contratos permanentes de trabalho, comparativamente aos contratos temporários. Uma possível explicação desse resultado pode estar associada à dupla jornada da mulher no mercado de trabalho (afazeres domésticos e trabalho), o que retira de muitas dessas a condição de disputar igualitariamente com os homens as melhores oportunidades de emprego em um mercado cada vez mais competitivo. De acordo com Lazear e Rosen (1990), observa-se com mais frequência mulheres com vínculo temporário do que homens, porque essas teriam menos disponibilidade de tempo para demonstrar dedicação ao trabalho, comparativamente aos homens, mais propensos a fazer altos investimentos na sua carreira profissional. ${ }^{6}$

Sobre a faixa etária, ainda na Tabela 1, pode-se observar que os trabalhadores mais jovens (18 a 25 anos) possuem maior participação nos empregos temporários, ao passo que os mais velhos (acima de 25 anos) tendem a se ocupar nos trabalhos com vínculo permanente de emprego. Acredita-se que tal fato seja reflexo principalmente da própria característica do trabalhador jovem de ser mais rotativo no mercado de trabalho em busca da ocupação que considere ideal, o que faz com que sua inserção ocupacional, muitas vezes, seja feita através de vínculos temporários de emprego visando adquirir experiência profissional e reduzir os custos para o empregador. Isso explica o porquê de os chefes de família, responsáveis pelo sustento financeiro da família, apresentarem percentual significativamente maior nos vínculos permanentes em relação ao temporário.

No que respeita o nível de escolaridade, nota-se que não existem maiores diferenças entre os tipos de contrato.

\footnotetext{
${ }^{6}$ Nannicini (2004), para o mercado de trabalho italiano, encontrou que a participação dos homens (em relação às mulheres) aumenta no emprego temporário.

Diferentemente de Engellandt e Riphahn (2005), Green e Heywood (2007) e Bradley et al. (2007).
} 
Em ambos, os trabalhadores com níveis mais elevados (nível superior) são maioria. Esse mesmo resultado foi encontrado nos trabalhos de Engellandt e Riphahn (2005), mostrando que não é o tipo de contrato que diferencia o perfil educacional do trabalhador a ser contratado.

Além das características pessoais do trabalhador, as características do emprego também foram analisadas. No que concer-

\section{Tabela 2_Características dos trabalhadores, segundo o tipo de contrato, em percentual - 2006 e 2007}

\begin{tabular}{l|lll} 
Características & Permanente & Temporário \\
\hline
\end{tabular}

Probabilidade de subocupaçáo por insuficiência de horas

efetivamente trabalhadas

\begin{tabular}{l|r|r}
\hline Mulher & 2,45 & 10,45 \\
\hline Homem & 1,62 & 6,87 \\
\hline Total & 1,93 & 8,61 \\
\hline
\end{tabular}

Probabilidade subremuneraçáo segundo o rendimento mensal habitualmente recebido pelo trabalhador

\begin{tabular}{l|r|r}
\hline Mulher & 12,22 & 8,60 \\
\hline Homem & 10,38 & 14,47 \\
\hline Total & 11,07 & 11,61 \\
\hline Probabilidade de ausência no trabalho & \multicolumn{2}{|r}{} \\
\hline Mulher & 3,22 & 3,37 \\
\hline Homem & 2,46 & 1,60 \\
\hline Total . . . . . . . . . . . . . . . . . . . . . . . . . 2,90 & $\ldots . . .2,40$ \\
\hline
\end{tabular}

Fonte: Pesquisa Mensal de Emprego (2006 e 2007). ne à duração no emprego, os trabalhadores com vínculo permanente possuem tempo maior no emprego comparativamente aos com vínculo temporário. Isso ocorre devido ao vínculo temporário ter explícito a data de seu término, que, segundo a Lei Trabalhista $\mathrm{n}^{\circ}$ 6.019, não pode ser maior do que seis anos.

Detalhando um pouco tais variáveis de interesse, descreve-se na Tabela 2 a probabilidade de subocupação, de subremuneração e ausência, conforme o sexo do trabalhador. Para o grupo de trabalhadores com tipo de contrato permanente, foi observado que as mulheres apresentam percentual superior ao dos homens no que respeita à subocupação em termos de horas $(2,45 \%$ contra 1,62\%), à subremuneração (12,22\% contra 10,38\%) e à ausência no trabalho (3,22\% contra $2,46 \%)$. Já para os trabalhadores com vínculo temporário de emprego, essa situação prevalece apenas na subocupação por insuficiência de horas trabalhadas e na ausência no trabalho, uma vez que, em relação à subocupação, segundo o rendimento mensal habitualmente recebido, os homens são maioria $(14,47 \%$ contra $8,60 \%)$.

\section{4_Estratégia empírica}

Este artigo se propóe a responder a duas perguntas. A primeira delas é verificar se existem evidências de que o trabalhador 
temporário é mais dedicado ao trabalho do que o permanente. A segunda é levantar se tal dedicação varia entre gênero do trabalhador.

Na primeira pergunta, seguiu-se a estratégia adotada por Engellandt e Riphahn (2005), utilizando-se para análise o estimador probit com efeito aleatório (random effect probit).

No artigo, as informaçóes selecionadas da PME constituem um painel finito $\operatorname{com} \mathrm{T}=2$ e $\mathrm{N} \rightarrow \infty$. A hipótese por trás dessa metodologia é que o efeito fixo é uma variável aleatória não correlacionada com os regressores. ${ }^{7}$ As variáveis de interesse são as medidas de esforço e assiduidade. Para controlar pelo efeito composição, utilizam-se como controles variáveis que visam captar as condiçóes socioeconômicas das famílias e as características do emprego, já descritas na Tabela 1 .

Estima-se, assim, a equação (4) abaixo.

$$
\begin{aligned}
& \text { Esforço }{ }_{i t}=\alpha_{1}+\alpha_{2} \text { Tempo }+ \\
& +\alpha_{k} \text { Familias }+\alpha_{j} \text { Mercado }+\varepsilon_{i t}
\end{aligned}
$$

Em seguida, será testado se o efeito do tipo de contrato sobre o empenho do trabalhador varia com o gênero. Para tanto, acrescenta-se na equação (4) uma dummy de interação entre gênero e tipo de contrato.

Engellandt e Riphahn (2005) alertam para duas possíveis fontes de endogeneidade nos procedimentos acima. Por um lado, os trabalhadores temporários podem ser "negativamente selecionados" por conta da baixa motivação/habilidade visto que aceitam as condiçóes impostas a esse tipo de contrato; por outro, esses podem ser "positivamente selecionados", dado que possuem baixa aversão ao risco, uma vez que aceitam essas condiçóes de contrato porque esperam melhores opçóes de trabalho no futuro. Sendo assim, torna-se necessário investigar se tais impactos estão gerando endogeneidade.

Com esse intuito, observam-se os indivíduos cujo contrato de trabalho se modificou de temporário para permanente entre os dois períodos da análise e tenta-se identificar as implicaçooes dessa mudança sobre as variáveis de esforço. Para tanto, estimam-se as equaçóes (5) e (6).

Em todas as estimações, visando controlar a heterogeneidade regional, são incluídas dummies para todas as regióes metropolitanas presentes na amostra, especificamente: Recife (RMR), Salvador (RMS), Belo Horizonte (RMBH), Rio de Janeiro (RMRJ), São Paulo (RMSP) e Porto Alegre (RMPA).
${ }^{7}$ Detalhes sobre essa técnica de estimação, ver Cameron e Trivedi (2009) 
Esforço $_{i t}=\alpha_{1}+\alpha_{2}$ Temp $+\alpha_{3}$ Temp $_{t}+\alpha_{4}$ Temp $_{t-1}$ Perm $_{t}+\alpha_{k}$ Familias $+\alpha_{j}$ Mercado $+\varepsilon_{i t}$

Esforço $_{i t}=\alpha_{1}+\alpha_{2}$ Temp $+\alpha_{3}$ Temp $_{t-1}$ Temp $_{t}+\alpha_{4} \operatorname{Temp}_{t-1}$ Perm $_{t}+\alpha_{k}$ Familias $+\alpha_{j}$ Mercado $+\varepsilon_{i t}$

${ }^{8}$ Este resultado pode significar que a falta ao trabalho não é uma característica peculiar de determinado grupo ocupacional.

\section{5_Resultados}

A análise da estratégia empírica começa com os resultados das estimaçóes do probit com efeito aleatório, para as variáveis de esforço, na Tabela 3, abaixo. Os coeficientes estimados para as proxies de esforço (subocupação e subremuneração) confirmam a existência de comportamentos diferentes para os trabalhadores com vínculos temporário e permanente de emprego. Em ambos os casos, os coeficientes foram significantes, e a análise do sinal sugere maior esforço por parte dos trabalhadores temporários. Ou seja, após controle das características do indivíduo e do emprego, observa-se que os trabalhadores temporários estão menos subocupados e são em sua maioria subremunerados, sugerindo assim maior dedicação ao trabalho. Finalmente, quando a análise é feita sobre a assiduidade ao trabalho, não é possível identificar diferenças de comportamento entre as duas categorias de trabalhadores. ${ }^{8}$
Os coeficientes das variáveis de característica pessoal do trabalhador sugerem que as mulheres, os trabalhadores mais jovens, os ocupados no setor privado da economia, os ocupados nas menores empresas e aqueles com menos tempo de emprego tendem a apresentar sinais de esforço significativamente maiores. Novamente, é possível observar que os coeficientes das variáveis referentes aos níveis de escolaridade não apresentaram significância, não sendo, portanto, característica intrínseca a determinado grupo de trabalhadores.

Uma informação adicional diz respeito aos coeficientes estimados para a variável dummy região metropolitana. Tendo a Região Metropolitana de Salvador como base, os resultados indicam que, nas regióes do Nordeste (Recife e Salvador), o nível de esforço dos trabalhadores tende a ser menor, tanto no referente à subocupação quanto à subremuneração. Tal resultado é esperado, uma vez que nessas regióes a concorrência no mercado de trabalho é menor. 
Tabela 3_Estimação do modelo probit de efeitos aleatórios, segundo proxies de esforço - 2006 e 2007

\begin{tabular}{|c|c|c|c|c|c|c|}
\hline \multirow{2}{*}{ Características } & \multicolumn{2}{|l|}{ Subocupação } & \multicolumn{2}{|c|}{ Subremuneração } & \multicolumn{2}{|l|}{ Ausência } \\
\hline & Coef. & Erro padrão & Coef. & Erro padrão & Coef. & Erro padrão \\
\hline Contrato temporário & $-0,091^{* * *}$ & 0,054 & $0,434^{*}$ & 0,063 & $-0,029$ & 0,087 \\
\hline Homem & $-0,247^{*}$ & 0,023 & $-0,160^{*}$ & 0,037 & $-0,220^{* * *}$ & 0,034 \\
\hline Chefe & $-0,093^{*}$ & 0,025 & 0,034 & 0,041 & 0,054 & 0,036 \\
\hline De 25 a 30 anos & $-0,278^{*}$ & 0,032 & $-0,052$ & 0,052 & $0,133^{* *}$ & 0,055 \\
\hline De 31 a 40 anos & $-0,458^{*}$ & 0,033 & $-0,036$ & 0,053 & $0,127^{* *}$ & 0,054 \\
\hline De 41 a 50 anos & $-0,556^{*}$ & 0,037 & $-0,149^{* *}$ & 0,061 & $0,207^{*}$ & 0,056 \\
\hline De 51 a 70 anos & $-0,573^{*}$ & 0,044 & $-0,295^{*}$ & 0,080 & $0,179^{*}$ & 0,065 \\
\hline Escolaridade (de 1 a 3 anos) & $-0,125$ & 0,088 & 0,099 & 0,216 & $-0,102$ & 0,150 \\
\hline Escolaridade (de 4 a 7 anos) & $-0,380^{*}$ & 0,079 & 0,143 & 0,195 & $-0,157$ & 0,133 \\
\hline Escolaridade (de 8 a 10 anos) & $-0,594^{*}$ & 0,080 & 0,055 & 0,196 & $-0,095$ & 0,133 \\
\hline Escolaridade (11 ou mais anos) & $-1,208^{*}$ & 0,079 & 0,131 & 0,193 & $-0,153$ & 0,130 \\
\hline Setor privado & $0,409^{*}$ & 0,062 & $-0,345^{*}$ & 0,060 & $-0,124^{* *}$ & 0,058 \\
\hline Tempo (até 1 mês) & $0,577^{*}$ & 0,089 & $0,407^{*}$ & 0,128 & $-0,301$ & 0,199 \\
\hline Tempo (de 1 mês até 1 ano) & $0,403^{*}$ & 0,027 & $0,223^{*}$ & 0,044 & $-0,598^{*}$ & 0,062 \\
\hline Tempo (de 1 ano até 2 anos) & $0,325^{*}$ & 0,029 & 0,008 & 0,052 & $-0,125^{*}$ & 0,046 \\
\hline Tamanho (1 a 5 trabalhadores) & $-0,384^{*}$ & 0,044 & $-0,206^{*}$ & 0,078 & 0,007 & 0,088 \\
\hline Tamanho (6 a 10 trabalhadores) & $-0,686^{*}$ & 0,028 & $-0,324^{*}$ & 0,050 & $0,209^{*}$ & 0,059 \\
\hline \multicolumn{7}{|l|}{ Efeitos fixos controlados } \\
\hline Ano $($ dummy) & $-0,101^{*}$ & 0,021 & 0,034 & 0,034 & 0,004 & 0,030 \\
\hline $\operatorname{RMR}($ dummy) & $0,070^{* * *}$ & 0,042 & $-0,030$ & 0,066 & $0,177^{* *}$ & 0,080 \\
\hline RMBH (dummy) & $-0,598^{*}$ & 0,039 & $-0,144^{*}$ & 0,056 & $0,483^{*}$ & 0,064 \\
\hline RMRJ (dummy) & $-0,469 *$ & 0,034 & $-0,584^{*}$ & 0,063 & 0,017 & 0,065 \\
\hline RMSP (dummy) & $-0,906^{*}$ & 0,038 & $-0,471^{*}$ & 0,060 & 0,091 & 0,065 \\
\hline RMPA (dummy) & $-0,935^{*}$ & 0,043 & $-0,417^{*}$ & 0,065 & $0,341^{*}$ & 0,066 \\
\hline Constante & $0,753^{*}$ & 0,110 & $-1,237^{*}$ & 0,219 & $-1,978^{*}$ & 0,168 \\
\hline Rho & 0,003 & 0,001 & 0,049 & 0,066 & 0,000 & 0,001 \\
\hline Log Likelihood & $8.995,677$ & 0,001 & $-3.108,57$ & 0,001 & $-3.929,38$ & 0,001 \\
\hline Número de observaçóes & & 31.704 & & 31.704 & & 31.70 \\
\hline
\end{tabular}

Fonte: Pesquisa Mensal de Emprego (2006 e 2007).

Nota: ${ }^{* *},{ }^{* *} \mathrm{e}^{*}$ indicam significância estatística $10 \%, 5 \%$ e1\%, respectivamente. 
Tabela 4_Estimação do modelo probit de efeitos aleatórios, segundo o tamanho da empresa 2006 e 2007

\begin{tabular}{|c|c|c|c|}
\hline Variáveis & Coef. & Erro padrão & $\begin{array}{l}\text { Efeito predito do } \\
\text { contrato temporário }\end{array}$ \\
\hline \multicolumn{4}{|l|}{ Subocupado em termos de horas } \\
\hline \multicolumn{4}{|l|}{ Tamanho (1 a 5 trabalhadores) } \\
\hline Contrato temporário (3.232 observações) & 0,122 & 0,133 & $4,239 \%$ \\
\hline \multicolumn{4}{|l|}{ Tamanho (6 a 10 trabalhadores) } \\
\hline Contrato temporário (1.998 observações) & $-0,447^{* *}$ & 0,241 & $2,953 \%$ \\
\hline \multicolumn{4}{|l|}{ Tamanho (11 ou mais trabalhadores) } \\
\hline Contrato temporário (26.474 observaçóes) & $-0,114^{* *}$ & 0,064 & $4,302 \%$ \\
\hline \multicolumn{4}{|l|}{ Subremuneração salarial } \\
\hline \multicolumn{4}{|l|}{ Tamanho (1 a 5 trabalhadores) } \\
\hline Contrato temporário (3.232 observaçōes) & $0,378^{* *}$ & 0,166 & $70,486 \%$ \\
\hline \multicolumn{4}{|l|}{ Tamanho (11 ou mais trabalhadores) } \\
\hline Contrato temporário (26.474 observaçóes) & $0,444^{*}$ & 0,465 & $57,390 \%$ \\
\hline
\end{tabular}

Fonte: Pesquisa Mensal de Emprego (2006 e 2007).

Notas: $1 .{ }^{* * *},{ }^{* *} \mathrm{e}^{*}$ indicam significância a $10 \%, 5 \% \mathrm{e} \%$, respectivamente. 2 . No referente à subocupação em termos de remuneraçẫo, a empresa com 6 a 10 trabalhadores não apresentou convergência, impossibilitando sua estimação. 3. Todos os modelos foram controlados pelas mesmas covariáveis da Tabela 3 .

Com o intuito de captar o impacto do tamanho da empresa no esforço (Tabela 4), será estimado mais uma vez um modelo probit de efeitos aleatórios, com os mesmos controles do anterior; agora, entretanto, as variáveis dependentes serão apenas as duas que se mostraram significantes na Tabela 3 (subocupação e subremuneração), e a análise ocorrerá apenas sobre o número de funcionários.

A Tabela 4 sugere que, nas empresas maiores (com maior número de funcionários), o nível de dedicação ao trabalha- dor tende a ser maior do que nas empresas menores. Em módulo, observa-se redução dos coeficientes ligados à variável subocupação à medida que cresce o tamanho da empresa, ou seja, quanto menos funcionários subocupados, maior a dedicação. De forma análoga, os coeficientes das variáveis subremuneração são crescentes com o número de funcionários, ou seja, quanto maior a empresa, maior o esforço.

O resultado acima pode ser explicado, primeiro, pelas chances de a mudança de contrato de temporário para per- 
Tabela 5_Estimação do modelo probit de efeitos aleatórios segundo proxies de esforço e sexo - 2006 e 2007

\begin{tabular}{|c|c|c|c|c|}
\hline Variáveis & $\begin{array}{l}\text { Subocupaçăo } \\
\text { Coef. }\end{array}$ & Erro padrão & $\begin{array}{l}\text { Subremuneraçăo } \\
\text { Coef. }\end{array}$ & Erro padrão \\
\hline Contrato temporário & 0,042 & 0,069 & $0,409^{*}$ & 0,085 \\
\hline Mulher & $0,260^{*}$ & 0,023 & $0,154^{*}$ & 0,039 \\
\hline Mulher $x$ contrato temporário & $-0,497^{*}$ & 0,175 & 0,101 & 0,133 \\
\hline Mulher $x$ contrato temporário $x$ setor privado & 0,251 & 0,189 & $-0,095$ & 0,154 \\
\hline Rho & 0,000 & 0,000 & 0,047 & 0,065 \\
\hline Log Likelihood & $8.999,166$ & 0,001 & $-3108,2605$ & 0,001 \\
\hline Número de observaçóes & & 31.704 & & 31.704 \\
\hline
\end{tabular}

Fonte: Pesquisa Mensal de Emprego (2006 e 2007).

Notas: $1 .{ }^{* * *},{ }^{* *} \mathrm{e}^{*}$ indicam significância estatística $10 \%, 5 \%$ e1\%, respectivamente. 2 . Todos os modelos foram controlados pelas mesmas covariáveis da Tabela 3 .

manente ser maior quanto maior for a empresa. Segundo, pela distância entre o chefe e o funcionário existente nas empresas maiores. Neste caso, a melhor forma de o empregado ser visto pelo chefe é pelos caminhos sugeridos no artigo.

$\mathrm{Na}$ Tabela 5 será investigada de que forma o gênero interfere no nível de dedicação do trabalhador. Os resultados descritos, apesar de a maioria das variáveis de interação analisadas não os apresentarem, mostram que existe diferença significativa conforme o sexo do trabalhador. Pois, tanto na subocupação $(0,260)$ quanto na subremuneração $(0,154)$, os coeficientes positivos, e significantes, indicam que a dedicação das mulheres no emprego é superior a dos homens, em média. Por sua vez, quando analisamos a variável de interação mulher e contrato temporário, o sinal negativo do coeficiente estimado $(-0,497)$ para a proxy de esforço subocupação mostra que a direção do efeito do esforço para as mulheres é contrária ao efeito estimado para os homens, e, portanto, que as mulheres com vínculo temporário são menos esforçadas comparativamente aos homens. A possível explicação, já bastante difundida na literatura econômica, está baseada nas obrigaçôes familiares que reduzem o tempo da mulher, principalmente na jornada de trabalho.

Por fim, a análise da possível interferência de fatores não observados no perfil de determinado grupo ocupacional foi retratada nas Tabelas 6 e 7. A ideia em questão é tentar verificar se existe diferença significativa de comportamento entre os trabalhadores temporários e os 
permanentes, caso seu vínculo empregatício se modifique ao longo do período estudado (hipótese 3).

Dada as variáveis de controle de capital humano e das características do emprego (as mesmas utilizadas na Tabela 3), investigamos tal hipótese adicionando uma variável que descreve se a pessoa ocupada com vínculo permanente foi um trabalhador com vínculo temporário no período anterior. Primeiramente, a Tabela 6 mostra os resultados da estimação do modelo probit de efeitos aleatórios dos determinantes para a proxy subocupação no período $t$. Os números indicam que o coeficiente estimado para os trabalhadores com contrato temporário no período completo $(0,412)$ é fortemente afetado pela variável adicional de controle, e que o indicador defasado do vínculo contratual estimado (-0,056) é insignificante, o que quer dizer que, uma vez que no período anterior $(\mathrm{t}-1)$ o trabalhador encontrava-se com vínculo temporário de emprego, o seu esforço não diferiu significativamente daqueles trabalhadores que durante todo o período estiveram com vínculo permanente. Esse resultado fornece um indicativo contra a seleção endógena nos vínculos temporários de emprego.

Tabela 6_Estimação do modelo probit de efeitos aleatórios para os determinantes da subocupação no período t: efeitos dinâmicos do contrato temporário - 2006 e 2007

\begin{tabular}{|c|c|c|c|c|}
\hline Variáveis & $\begin{array}{l}\text { Estimação } 1 \\
\text { Coef. }\end{array}$ & Erro padrão & $\begin{array}{l}\text { Estimação } 2 \\
\text { Coef. }\end{array}$ & Erro padrão \\
\hline \multicolumn{5}{|l|}{ Referência: Contrato permanente em $\mathrm{t}-1$ e $\mathrm{t}$} \\
\hline Contrato temporário em $t$ & $0,412 *$ & 0,090 & & - \\
\hline Contrato permanente em $t$ e temporário em $t-1$ & $-0,056$ & 0,126 & & - \\
\hline \multicolumn{5}{|l|}{ Referência: Contrato permanente em t } \\
\hline Contrato temporário em $t$ e $t+1$ & - & - & $-0,089$ & 0,126 \\
\hline Contrato temporário em $t$ e permanente em $t+1$ & - & - & 0,203 & 0,391 \\
\hline Rho & 0,052 & 0,065 & 0,051 & 0,064 \\
\hline Log Likelihood & $3.122,173$ & 0,000 & $-3.132,031$ & 0,000 \\
\hline Número de observaçóes & & 31.704 & & 31.704 \\
\hline
\end{tabular}

Fonte: Pesquisa Mensal de Emprego (2006 e 2007).

Notas: $1 .{ }^{* *},{ }^{* *} \mathrm{e}^{*}$ indicam significância estatística $10 \%, 5 \%$ e $1 \%$, respectivamente. 2 . Todos os modelos foram controlados pelas mesmas covariáveis da Tabela 3 . 
Sobre a possibilidade de que o esforço dos trabalhadores temporários seria impulsionado pelo grupo de trabalhadores "positivamente selecionados", a estimação da coluna 2 procura comparar o esforço dos trabalhadores temporários que permaneceram temporários e dos que alteraram seu vínculo contratual no período seguinte $(t+1)$. Os resultados, porém, não fornecem subsídios para afirmar ou descartar essa hipótese, visto que os coeficientes não foram significantes, tanto para os que permaneceram com vínculo temporário quanto para os que alteraram seus vínculos (positivamente selecionados).
Análise similar foi feita para a proxy subremuneração no período $t$ cujos resultados estáo dispostos na Tabela 7 , abaixo. De forma similar ao diagnóstico anterior, os resultados mostram que o coeficiente estimado para o trabalhador com vínculo temporário de emprego $(-0,169)$ é influenciado pela variável adicional de controle (neste caso, negativamente), e que o indicador defasado do vínculo contratual $(0,026)$ apresentou coeficiente insignificante, reforçando, portanto, a hipótese de que a dedicação do trabalhador temporário não difere significativamente da prevista pelos trabalha-

Tabela 7_Estimação do modelo probit de efeitos aleatórios para os determinantes da subremuneração no período t: efeitos dinâmicos do contrato temporário - 2006 e 2007

\begin{tabular}{|c|c|c|c|c|}
\hline Variáveis & $\begin{array}{l}\text { Estimação } 1 \\
\text { Coef. }\end{array}$ & $\begin{array}{l}\text { Erro } \\
\text { padrão }\end{array}$ & $\begin{array}{l}\text { Estimação ? } \\
\text { Coef. }\end{array}$ & Erro padrão \\
\hline \multicolumn{5}{|l|}{ Referência: Contrato permanente em $\mathrm{t}-1$ e $\mathrm{t}$} \\
\hline Contrato temporário em $t$ & $-0,169^{* *}$ & 0,084 & - & - \\
\hline Contrato permanente em $t$ e temporário em $t-1$ & 0,026 & 0,069 & - & - \\
\hline \multicolumn{5}{|l|}{ Referência: Contrato permanente em $t$} \\
\hline Contrato temporário em $t$ e $t+1$ & - & - & 0,031 & 0,069 \\
\hline Contrato temporário em $t$ e permanente em $t+1$ & - & - & $-0,120$ & 0,329 \\
\hline Rho & 0,015 & 0,035 & 0,015 & 0,034 \\
\hline Log Likelihood & $-8.994,921$ & 0,000 & $-8.996,932$ & 0,000 \\
\hline Número de observaçóes & & 31.704 & & 31.704 \\
\hline
\end{tabular}

Fonte: Pesquisa Mensal de Emprego (2006 e 2007).

Notas: $1 .{ }^{* *},{ }^{* *} \mathrm{e}^{*}$ indicam significância estatística $10 \%, 5 \%$ e 1\%, respectivamente. 2 . Todos os modelos foram controlados pelas mesmas covariáveis da tabela 3 . 
dores de vínculo permanente em todo o período. Tal resultado, porém, deve ser visto com cautela, haja vista que, mais uma vez, a segunda estimação (coluna 2 da Tabela 7) não descarta a hipótese de que o esforço dos trabalhadores temporários estaria sendo impulsionado pelo grupo de trabalhadores "positivamente selecionados", visto que os coeficientes estimados foram insignificantes.

\section{6_Considerações finais}

Este artigo procurou analisar, de forma comparativa, o comportamento no mercado dos trabalhadores com contrato de trabalho temporário e dos trabalhadores com contrato de trabalho permanente, através de proxies de esforço. As informaçóes foram obtidas nos microdados da Pesquisa Mensal de Emprego (PME), de 2006 e 2007.

$\mathrm{O}$ artigo procurou analisar se as desvantagens contratuais dos trabalhadores com vínculo temporário de emprego em relaçáo àqueles que possuem vínculos permanentes implicariam incentivos adicionais para os contratados temporariamente. De acordo com a literatura internacional, tal fato se baseia na hipótese de que níveis mais elevados de dedicação/ esforço tenderiam a aumentar as chances de um trabalhador com vínculo tempo- rário se tornar um trabalhador com vínculo permanente.

Para testar essa hipótese, utilizamos o modelo probit de efeitos aleatórios (random effect probit) através do uso de proxies que visavam identificar os esforços desenvolvidos pelos trabalhadores no emprego. Neste contexto, três variáveis foram adotadas: trabalhador subocupado (aqueles que estão trabalhando menos de 40 horas semanais e que gostariam de trabalhar horas adicionais), trabalhador subremunerado (trabalhadores subremunerados segundo a proporcionalidade entre rendimento habitualmente recebido e as horas habitualmente trabalhadas) e assiduidade (trabalhador que faltou o trabalho).

Verificou-se que existem diferenças significativas de perfil entre os trabalhadores, conforme o seu vínculo contratual. De maneira geral, as mulheres se inserem mais facilmente nos contratos temporários, assim como apresentam níveis de esforço maiores comparativamente aos homens. Outra característica importante desse grupo é sua faixa etária, composta, na maioria, de jovens; no entanto, tal característica não apresenta correlação com níveis escolares mais baixos, haja vista a grande incidência de categorias profissionais de nível elevado de escolaridade.

Os resultados das estimaçóes do modelo probit de efeitos aleatórios con- 
firmaram comportamentos diferentes para os trabalhadores com vínculos temporário e permanente de emprego. Em relação à variável subocupação, o sinal negativo do coeficiente estimado $(-0,091)$ mostra que os trabalhadores com contrato temporário estão menos dispostos, comparativamente, a ofertar horas adicionais. Em relação à subremuneração, o sinal positivo estimado $(0,434)$ indica que os trabalhadores com vínculo temporário têm chances maiores de receber remuneração inferior a do mínimo, ou seja, de ser subremunerados. E, em relação às faltas ao trabalho, o coeficiente estimado não apresentou significância estatística, de forma que não foi possível inferir conclusões acerca do comportamento do trabalhador conforme o tipo de vínculo empregatício. Com relação às estimações com as variáveis de interação, os resultados indicam que tanto na proxy subocupação quanto na subremuneração, a dedicação das mulheres no emprego, na média, é superior a dos homens. Por sua vez, a análise da possível interferência de fatores não observados na determinação no perfil de determinado grupo ocupacional, embora com ressalvas, indica que não existe diferença significativa de comportamento entre os trabalhadores temporários e permanentes, conforme se verifique a mudança de seu vínculo empregatício ao longo do período estudado.
Finalizando, nossas evidências apontam para dois importantes resultados. Primeiro, sugerem fortemente a existência de informaçóes assimétricas no mercado de trabalho, sendo mais visível nas empresas de pequeno porte, visto que, nas empresas maiores, a assimetria de informação inerente aos riscos da contratação tende a ser menor. Isso provavelmente ocorre porque, quanto maior for o tamanho da empresa, maior tende a ser o seu investimento no recrutamento/seleção dos trabalhadores, o que deve estar associado provavelmente à incapacidade das empresas de extraírem o máximo de seus trabalhadores temporários, de os estimularem com ganhos de produtividade e promoção interna, fazendo com que esses se identifiquem cada vez mais com o ambiente interno da empresa. E, segundo, as estimações feitas não indicaram mudança significativa de comportamento entre os trabalhadores, conforme se modifique o seu vínculo contratual, não sendo possível confirmar para o caso brasileiro, ou seja, não é possível afirmar que os trabalhadores com vínculo de trabalho temporário são mais esforçados do que os com vínculo permanente. 


\section{Referências bibliográficas}

AMADEO, E.; CAMARGO, J. M. Instituiçôes e o mercado de trabalho brasileiro. In CAMARGO, J. M. (Org.) Flexibilidade no mercado de trabalho no Brasil. Rio de Janeiro, 1996.

BARMBY, T. A.; ORME, C.; TREBLE, J. G. Worker absenteeism: An analysis using microdata. Economic Journal, v. 101, n. 405, p. 214-229, 1991.

BARBMY, T. G.. Worker absenteeism: A discrete hazard model with bivariate heterogeneity. Labour Economics, v. 9, n. 4, p. 469-476, 2002.

BARROS, R. P. de; CORSEUIL, C. H.; BAHIA, M. Labor market regulations and the duration of employment in Brazil. IPEA Texto para Discussão, no. 676, 1999.

BLANCHARD, O.; LANDIER, A. The perverse effects of partial labour market reform: FixedTerm contracts in France.

Economic Journal, v. 112, n. 480, p. 214-244, 2002.

BLANCHARD, Olivier.

Macroeconomia. 3. ed. São Paulo: Pearson, 2004.
BOOTH, A. L.; FRANCESCONI, M.; FRANK,

J. Temporary jobs: Stepping stones or dead ends?, Economic Journal, v. 112, n. 480, p. 189213, 2002.

\section{BRADLEY, S.; GREEN, C.;}

LEEVES, G. Employment contracts and effort: Why do temporary workers take less absence? Lancaster University Management School. Working Paper, 2007.

CAHUC, P.; POSTEIL-VINAY, F. Temporary jobs, employment protection and labor market performance. Labour Economics, v. 9, n. 1, p. 63-91, 2002.

CAMERON, A. Colin; TRIVEDI, Pravin K. Microeconometrics using Stata. Stata Press, 2009.

ENGELLANDT, A.; RIPHAHN, R. T. Temporary contracts and employee effort. Labour Economics, v. 12, p. 281299, 2005.

\section{ESTEVES, L. A. Salário}

eficiência e esforço de trabalho: Evidências da indústria brasileira de construção. Economia, Brasília (DF), v. 9, n. 2, p. 327-341, maio/ ago., 2008.
GOMES, Z. B.; LOURENÇO,

A. L. C. O Estado como empregador de última instância: Uma proposta de pleno emprego, estabilidade e condiçóes dignas de trabalho para o Brasil. Anais da ANPEC, 2008.

GREEN, C.; LEEVES, G. Casual employment and internal labour markets. Manchester School, v. 72, p. 658-676, 2004.

GREEN, C. P.; HEYWOOD, J. S. Are flexible contracts bad for workers? Evidence from Job Satisfaction Data. Lancaster University Management School. Working Paper, 2007.

HOLMLUND, B.; STORRIE, D. Temporary work in turbulent times: The Swedish experience. Economic Journal, v. 112, n. 480, p. 245-269, 2002.

ICHINO, A.; RIPHAHN, R. $\mathrm{T}$. The effect of employment protection on worker effort: A comparison of absenteeism during and after probation. IZA Discussion Paper, $\mathrm{n}^{\circ}$. 385, IZA Bonn / Germany, 2001.
JATOBA, J.; ANDRADE, E. G. L. de. A desregulamentação do mercado e das relaçóes de trabalho no Brasil: Potencial e limitações. Texto para discussão no 312, 1993.

JIMENO, J. F.; CORTÉS, L. T. Effort, absenteeism, and fixed term employment contracts. Revista Espanola de Economia, v. 13, n. 1, p. 105-119, 1996.

JOHANSON, P.; PALME, M. Do economic incentives affect work absence? Empirical evidence using Swedish Micro Data. Journal of Public Economics, v. 59, n. 2, p. 195-218, 1996.

JOHANSON, P.; PALME, M. Assessing the effect of public policy on worker absenteeism. Journal of Human Resources, v. 37, n. 2, p. 381-409, 2002.

LAZEAR, E. P.; ROSEN, S. Male-female wage differentials in job ladders. Journal of Labor Economics, v. 8, p. 106-123, 1990.

MANGAN, J. Workers without traditional employment: An international study of nonstandard work. Cheltenham: Edward Elgar, 2000. 
NANNICINI, T. The take-off temporary employment in the Italian market labour. European University Institute. Working paper Eco $\mathrm{n}^{\circ}$ 2004/9, 2004.

RIBAS, R. P.; SOARES, S.

S. D. O atrito nas pesquisas longitudinais: o caso da pesquisa mensal de emprego (PME/IBGE)

Estudos Econômicos, v. 40, nº1, p. 213-244. 2010.

RIPHAHN, R. T.;

THALMAIER, A. Behavioral effects of probation periods: An analysis of worker absenteeism. Jahrbücher für Nationalökonomie und Statistik, v. 221, n. 2, p. 179201, 2001.

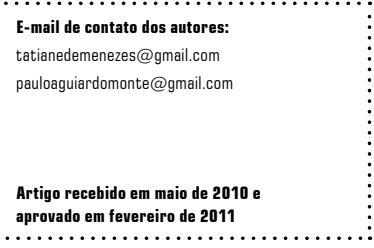

